Abstracta Iranica

Revue bibliographique pour le domaine irano-aryen

Volume 40-41 | 2019

Comptes rendus des publications de 2017-2018

\title{
Massimiliano Borroni. Il nuovo giorno dell'impero. Il capodanno solare dei califfi abbasidi
}

\author{
Alessia Zubani
}

\section{(2) OpenEdition}

1 Journals

\section{Édition électronique}

URL : http://journals.openedition.org/abstractairanica/50452

DOI : 10.4000/abstractairanica.50452

ISBN : 1961-960X

ISSN : 1961-960X

Éditeur :

CNRS (UMR 7528 Mondes iraniens et indiens), Éditions de l'IFRI

Référence électronique

Alessia Zubani, « Massimiliano Borroni. I/ nuovo giorno dell'impero. I/ capodanno solare dei califfi abbasidi », Abstracta Iranica [En ligne], Volume 40-41 | 2019, document 23, mis en ligne le 30 décembre 2019, consulté le 24 avril 2021. URL : http://journals.openedition.org/abstractairanica/50452 ; DOI https://doi.org/10.4000/abstractairanica.50452

Ce document a été généré automatiquement le 24 avril 2021

Tous droits réservés 


\title{
Massimiliano Borroni. Il nuovo giorno dell'impero. Il capodanno solare dei califfi abbasidi
}

\author{
Alessia Zubani
}

\section{RÉFÉRENCE}

Massimiliano Borroni. Il nuovo giorno dell'impero. Il capodanno solare dei califfi abbasidi.

Venezia : Edizioni Ca' Foscari, 2017, 212 p.

1 Le volume, qui fait suite à une thèse doctorale soutenue en 2015 à de l'Université Ca' Foscari (Venise), offre la première étude véritablement systématique sur le Nouvel An solaire iranien (nawrūz) dans les trois premiers siècles de la période abbasside (c. 750-1050). À travers l'analyse de sources historiographiques, littéraires et administratives produites dans la première époque abbasside, l'A. contextualise les pratiques liées aux fêtes du Nouvel An dans ses diverses manifestations. L'étude vise notamment à expliquer les raisons du succès rencontré par les festivités d'origine iranienne dans le milieu mésopotamien, où pour la première fois les élites locales adoptèrent le nawrūz. Dans ce but, l'A. étend son analyse à trois contextes différents : palatial, administratif et populaire.

2 Après une introduction d'ordre méthodologique (p. 9-28), le premier chapitre ( $p$. 29-126) examine les festivités de la cour califale. L'A. y retrace l'histoire mythique de la fête annuelle et il constate que l'adoption d'idéaux royaux iraniens à l'époque abbasside avait davantage une valeur politique légitimatoire.

3 Le deuxième chapitre (p. 127-170) se penche sur la centralité du nawrūz dans les pratiques administratives et fiscales de l'empire. D'après l'A., la persistance de ce référent calendaire s'explique notamment avec l'introduction dans le monde abbasside de nombreuses pratiques fiscales et administratives sassanides. 
4 L'ouvrage traite enfin des traditions populaires associées au nawrūz (p. 171-181). Comme l'A. le montre, la rareté des sources qui nous renseignant à ce sujet n'empêche pas pour autant d'essayer de définir, au moins de manière partielle, les célébrations populaires.

\section{AUTEURS}

\section{ALESSIA ZUBANI}

Doctorante EPHE, Mondes iranien et indien, Paris 